flow-mediated dilation was lower in patients with coronary aneurysms due to KD as compared with normal controls $(P<0.05)$. Arterial stiffness index was raised in KD group than in normal controls $(P<$ 0.05). There was no difference between the two groups in carotid intima-media thickness. The FMD was lower in KD patients with myocardial ischemia or ECG abnormalities than in patients without $(P<0.05)$, while no difference was found in FMD between patients with giant aneurysms and those with medium aneurysms.

Conclusions: The endothelial function in patients with coronary aneurysms due to Kawasaki disease is damaged, especially in patients with giant coronary aneurysm and myocardial ischemia.

609

\section{ECHOCARDIOGRAPHY AND ITS ROLE IN THE DIAGNOSIS AND PROGNOSIS OF CONGENITAL HEART DISEASE IN CHILDREN}

\author{
M. Kelmendi, R. Bejiqi, R. Retkoceri, \\ A. Batalli-Kepuska, L. Kryeziu \\ Cardiology, University Children's Hospital, \\ Prishtina, Albania
}

The most important thing in the congenital heart disease evaluation is early diagnosis, because almost all CHD, even the most complicated ones, are now operable.

Objective: To determine the frequency and pattern of CHD in our country and to underline the role of early diagnosis in the outcome of patients with CHD.

Material and methods: Retrospective study of children with CHD, examined at hospitalized at University Children's Clinic, Prishtina, from 2000 2006. Age from 1 mo to 18 years. Ecxept 2D color echocardiography, other non invasive techniques were also used for diagnosis: history, laboratory, $E C G$, chest $X$ ray, pulse oximetry.

Results: The number of children with $\mathrm{CHD}$ was 1671, including the simpliest to most complex CHD. According to cyanosis, there were 207 (12.4\%) cyanotic patients, while $1464(87.6 \%)$ have no cyanosis. The type of lesions were similar to those reported from other studies. The age when the diagnosis of $\mathrm{CHD}$ is performed was: Only $45 \%$ of children with CHD were diagnosed under the age of three years, the remaining $55 \%$ were diagnosed later, even at the age above ten years. It was probably the reason for a high number of complications in children with $\mathrm{CHD}$, such as : pulmonary hypertension (3.5\%) , heart failure ( $10 \%)$ and death (5.5\%).

Conclusion: Since echocardiography is sufficient for diagnosis of most CHD and has no adverse effects or hazards, echocardiography could be a routine in order to prevent late diagnosis of $\mathrm{CHD}$ and to escape complications.

\section{0}

\section{ROLE OF MAGNESIUM IN PREVENTING POSTOPERATIVE ARRYTHMIAS IN NEONATES AND INFANTS UNDERGOING THE ARTERIAL SWITCH OPERATION}

\author{
S. Chauhan ${ }^{1}$, Y.S. Verma ${ }^{1}$, A. Bisoi ${ }^{2}$
}

${ }^{1}$ Cardiac Anaesthesia, ${ }^{2}$ Cardiothoracic Surgery, All India Institute of Medical Sciences, New Delhi, India

\section{Objective:}

1. Magnesium levels in neonates and infants with Transposition of Great Arteries undergoing the Arterial Switch Operation.

2. Role of Magnesium supplementation in prevention of post operative arrythmias in these infants.

Material and methods: After ethical clearance and written informed consent from the parents, Neonates and infants undergoing the Arterial Switch operation were randomly assigned to one of two groups. Group 1 ( $n=25$ ) was given intravenous Magnesium Sulphate $30 \mathrm{mg} / \mathrm{kg}$ in $5 \mathrm{ml}$ Normal saline, immediately after cessation of cardiopulmonary bypass, while Group II $(n=25)$ was given $5 \mathrm{ml}$ of Normal saline as a placebo .Blood samples were taken after induction of anaesthesia, after stabilisation on cardiopulmonary bypass, during rewarming, and 4 hours after admission to the intensive care unit.The samples were analysed for arterial blood gases, and electrolytes including $\mathrm{Na}+, \mathrm{K}+$,ionised $\mathrm{Ca}++$, ionised $\mathrm{Mg}++$.Continuous ECG rhythm analysisand documentation of arrythmias was performed for 24 hours in the intensive care.

Results: Both the groups were comparable with regard to demographic data.Mean preoperative ionised $\mathrm{Mg}++$ levels were below normal in both the groups, at $0.30( \pm 0.11) \mathrm{mmol} / \mathrm{L}$ in group I and $0.30( \pm 0.8) \mathrm{mmol} / \mathrm{L}$ in group II. Serum ionised $\mathrm{Mg}++$ increased during rewarming period of cardiopulmonary bypass, in both groups. 